\title{
Evaluation of Current Status and Awareness Program of Urinary Tract Infection (UTI) at Chattogram in Bangladesh
}

\author{
Sadiya Chowdhury ${ }^{1}$ and Md Shahidul Islam ${ }^{2 *}$ \\ ${ }^{1}$ Student, Department of Pharmacy, University of Science and Technology Chittagong (USTC) Bangladesh \\ ${ }^{2}$ Assistant Professor, Department of Pharmacy, University of Science and Technology Chittagong (USTC) Bangladesh \\ *Corresponding author: Md Shahidul Islam, Assistant Professor, Department of Pharmacy, University of Science \& Technology \\ Chittagong (USTC), Bangladesh
}

\section{ARTICLE INFO}

Received: April 08, 2020

Published: 慧 May 20, 2020

Citation: Sadiya Chowdhury, MdShahidul Islam. Evaluation of Current Status and Awareness Program of Urinary Tract Infection (UTI) at Chattogram in Bangladesh. Biomed J Sci \& Tech Res 27(5)-2020. BJSTR. MS.ID.004552.

Keywords: Urinary tract infections; Survey; Chattogram

\begin{abstract}
Urinary tract infections (UTIs) are highly prevalent worldwide. Urinary tract infections (UTIs) are the inflammatory disorders of the urinary tract caused by the abnormal growth of pathogens. The purpose of this study was to determine the most frequent bacterial pathogens responsible for UTIs, to evaluate antibiotics used to treat such infection, to detect and evaluate the incidence of infection \& to review the current evidence of diagnosis, management of UTIs from the patients. A descriptive type of cross-sectional study design was used. The survey was carried out from November 2019 to February 2020, among 50 patients in the Urology Department of Chattogram Medical College Hospital (CMCH), Chattogram. According to this survey the highest proportion of patient's age range was from $21-30$ years which was $28 \% .68 \%$ of patients were male and the remaining $32 \%$ were female patients. $64 \%$ of patients were married and the remaining $36 \%$ were unmarried. The highest proportion of patients was illiterate regarding $46 \%$. The highest proportion of patients was from rural area which was $60 \%$.

The highest proportion of patients had frequency or urgency of urination with less urine output which was $32 \%$. The highest proportion of patients had done USG of KUB diagnosis for UTI which was $20 \%$. The highest proportion of patients had taken antibiotic therapy only during hospitalization which was $48 \%$. The highest proportion of patients had not taken any antibiotic which was 30\%. The highest proportion of patients had completed $50 \%$ course of treatment which was $52 \%$. The highest proportion of patients had genitourinary abnormalities as associated disease with UTI which was $34 \%$. In this research work, awareness program was carried out among the students of different teaching institutes, where the information about prevention and treatment of UTI had provided.
\end{abstract}

\section{Introduction}

Urinary tract infections (UTIs) are highly prevalent worldwide [1]. Urinary tract infections (UTIs) are the inflammatory disorders of the urinary tract caused by the abnormal growth of pathogens $[2,3]$. Urinary tract infection is known to cause short-term morbidity in terms of fever, dysuria, and lower abdominal pain (LAP) and may result in permanent scarring of the kidney [4,5]. Urinary tract infections may be asymptomatic, acute, chronic, and complicated or uncomplicated, and the clinical manifestations of UTIs depend on the portion of the urinary tract involved, the etiologic organisms, the severity of the infection, and the patient's ability to mount an immune response to it. Both asymptomatic and symptomatic UTIs pose a serious threat to public health care, hence reducing the quality of life and resulting into work absenteeism [6]. UTIs are most often due to bacteria (95\%), but may also include fungal and viral infection [7]. Several authors around the world have been reported the Gram negative bacteria of E.coli and Klebsiella spp. being the most frequent organisms causing UTIs [8-12]. E.coli causes 70-95\% 
upper and lower UTIs [13]. About 150 million people suffer from UTIs each year globally [14]. Urinary surgery or an exam of your urinary tract that involves medical instruments can both increase risk of developing a urinary tract infection.

\section{Materials and Method}

\section{Design}

A descriptive type of cross-sectional study design was used. All the data were collected through structured format in questionnaires. The sample sizes were statistically desirable, feasible and satisfactory and were approached randomly. The recording system was almost adequate and no other persons were engaged in collecting the data except the researcher so that the quality of the overall data was reliable.

\section{Place of Study}

The survey was carried out in the Urology Department of Chattogram Medical College Hospital (CMCH), Chattogram.

\section{Data Collection Period}

From November 2019 to February 2020.

\section{Survey Protocol}

For prospective cross-sectional encounter, pre-prepared questions were asked among 50 patients regarding UTI from Chattogram Medical College Hospital (CMCH), Chattogram, who agreed to participate were selected randomly. The patients were asked the questions by researcher herself which she filled in the questionnaire form. The questionnaire was to collect information on age, gender, marital status, level of education, residence, signs and symptoms, diagnostic test, antibiotic therapy, used antibiotic, duration of treatment and associated disease. The data from questionnaire were processed anonymously. Data were analyzed.

\section{Data complication and processing}

After complication of raw data, we stoned out and prepared a master table manually, keeping in view the objectives and variables.

\section{Data analysis and report writing}

Data were processed with the help of MS Excel and MS Word.

\section{Results and Discussion}

\section{Age range}

a. Comment: (Table 1) (Figure 1)

From the above figure it was seen that the highest proportion of patient's age range was from 21-30 years which was $28 \%$ and the least proportion of patient's age range was from 71-80 years which was only $2 \%$. Among the remaining $22 \%$ of patient's age range was from $61-70$ years, $16 \%$ of patient's age range was from 09-20 years, $12 \%$ of patient's age range was from $41-50$ years, $10 \%$ of patient's age range was from $31-40$ years and $10 \%$ of patient's age range was from 51-60 years.

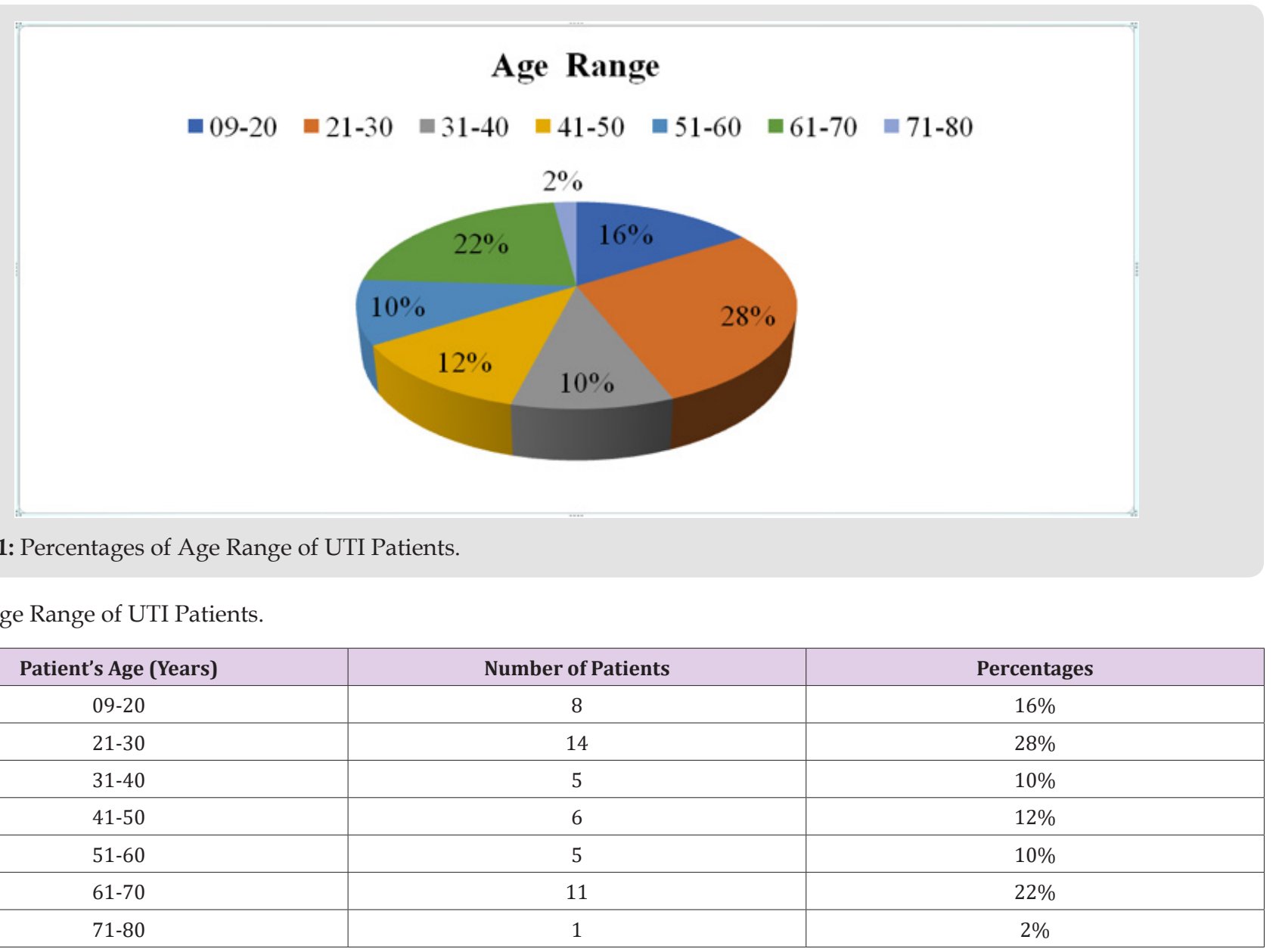




\section{Gender}

a. Comment (Table 2) (Figure 2)

From the above figure it was seen that $68 \%$ of patients were male and the remaining $32 \%$ were female patients.

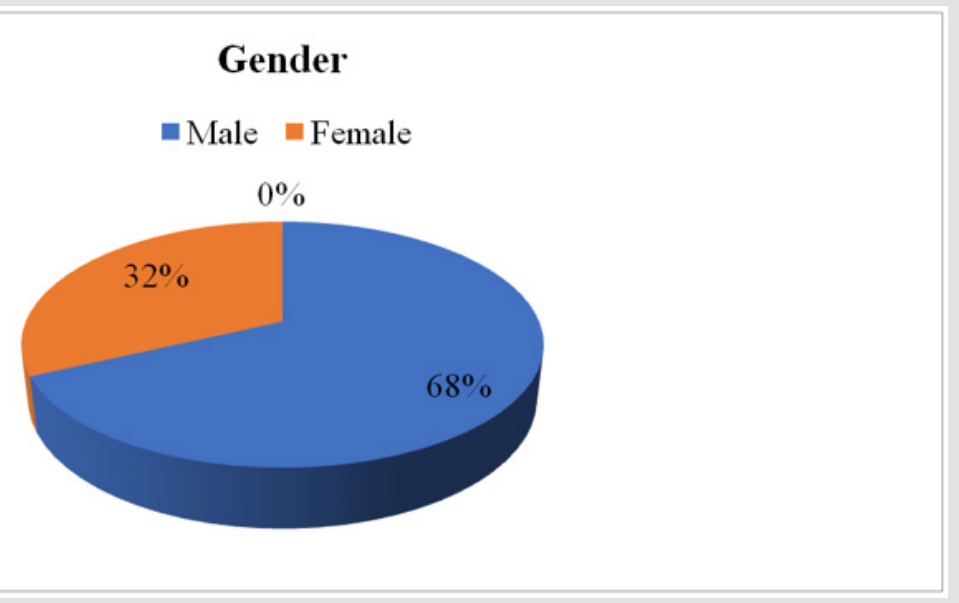

Figure 2: Gender of UTI Patients.

Table 2: Gender of UTI Patients.

\begin{tabular}{|c|c|c|}
\hline Gender & Number of Patients & Percentages \\
\hline Male & 34 & $68 \%$ \\
\hline Female & 16 & $32 \%$ \\
\hline
\end{tabular}

\section{Marital Status}

a. Comment (Table 3) (Figure 3)

From the above figure it was seen that $64 \%$ of patients were married and the remaining $36 \%$ were unmarried.

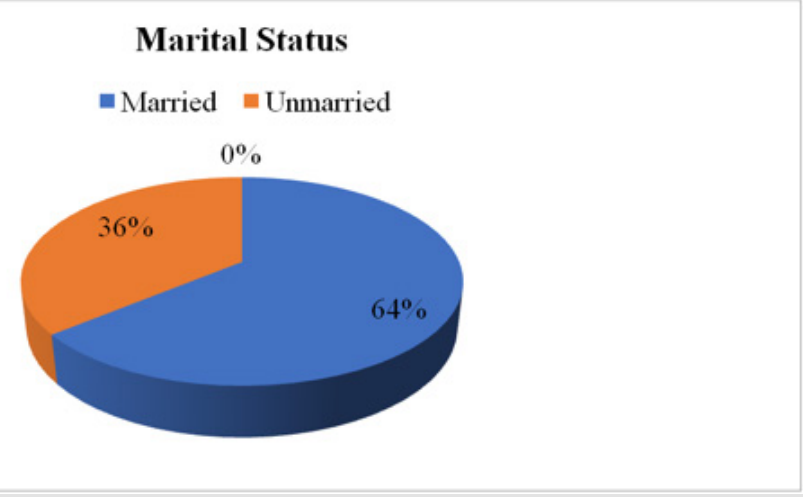

Figure 3: Percentages of Marital Status of UTI Patients.

Table 3: Marital Status of UTI Patients.

\begin{tabular}{|c|c|c|}
\hline Marital Status & Number of Patients & Percentages \\
\hline Married & $64 \%$ & 32 \\
\hline Unmarried & 18 & $36 \%$ \\
\hline
\end{tabular}

\section{Level of Education}

\section{a. Comment (Table 4) (Figure 4)}

From the above figure it was seen that the highest proportion of patients was illiterate regarding $46 \%$ and the least proportion had secondary education which was $6 \%$. Among the remaining, $16 \%$ of patients were educated with primary education, $12 \%$ had a bachelor's/ master's degree, 12\% were educated with higher secondary education and $8 \%$ were educated with lower secondary education. 


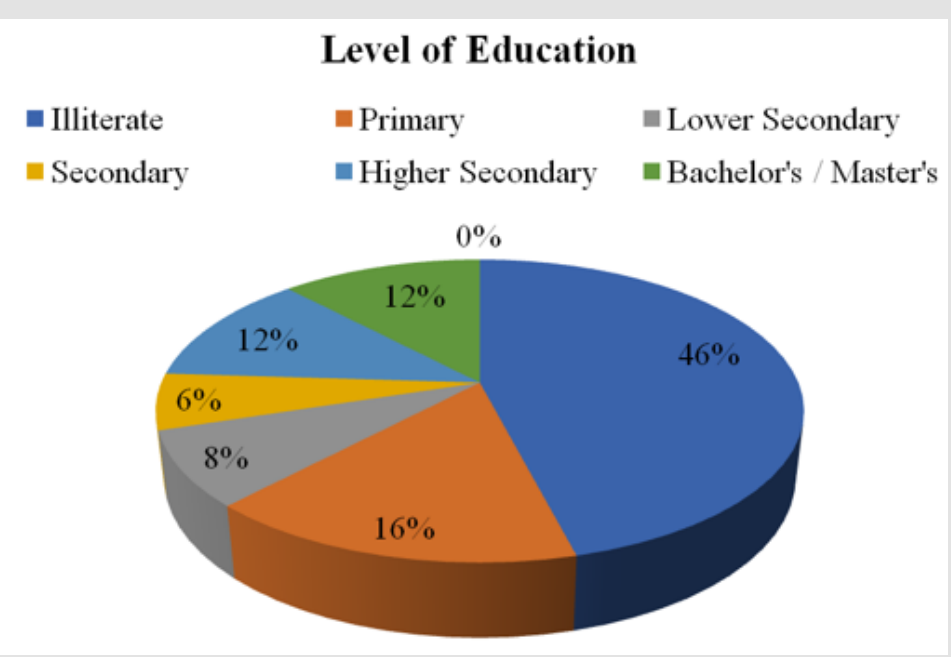

Figure 4: Percentages of Level of Education of UTI Patients.

Table 4: Level of Education of UTI Patients.

\begin{tabular}{|c|c|c|}
\hline Level of Education & Number of Patients & Percentages \\
\hline Illiterate & 23 & $46 \%$ \\
\hline Primary & 8 & $16 \%$ \\
\hline Lower Secondary & 4 & $8 \%$ \\
\hline Secondary & 3 & $6 \%$ \\
\hline Higher Secondary & 6 & $12 \%$ \\
\hline Bachelor's / Master's & 6 & $12 \%$ \\
\hline
\end{tabular}

\section{Residence}

\section{a. Comment (Table 5) (Figure 5)}

From the above figure it was seen that the highest proportion of patients was from rural area which was $60 \%$ and the least proportion was from slum area which was $14 \%$. The remaining $26 \%$ patients were from urban area.

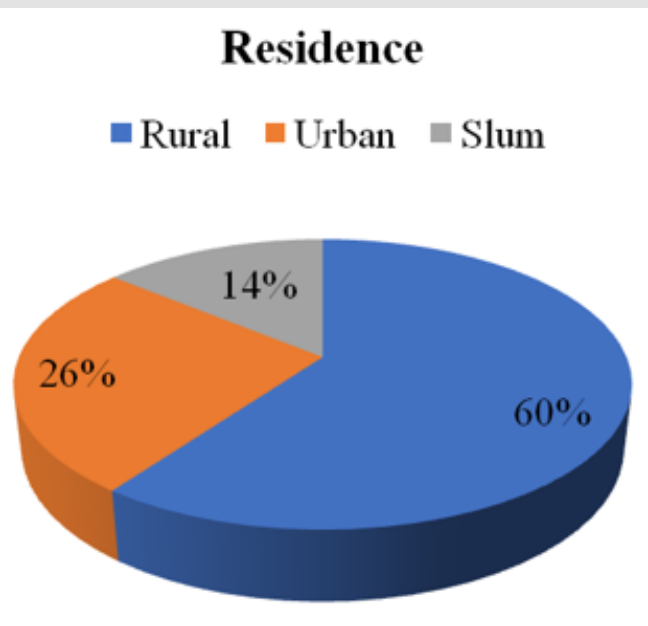

Figure 5: Percentages of Residence of UTI Patients.

Table 5: Residence of UTI Patients.

\begin{tabular}{|c|c|c|}
\hline Residence & Number of Patients & \multicolumn{2}{|c|}{ Percentages } \\
\hline Rural & 30 & $20 \%$ \\
\hline Urban & 13 & $26 \%$ \\
\hline Slum & 7 & $14 \%$ \\
\hline
\end{tabular}




\section{Signs and Symptoms}

\section{a. Comment (Table 6) (Figure 6)}

From the above figure it was seen that the highest proportion of patients had frequency or urgency of urination with less urine output which was $32 \%$ and the least proportion had sense of incomplete emptying of bladder which was only $2 \%$. Among the remaining $24 \%$ patients had pain in lower abdomen or back , $12 \%$ patients had dysturia (burning pain on urination), 10\% patients had cloudy, dark, bloody or strange-smelling urine, $8 \%$ patients had fever (high grade) or chills or shaking, $6 \%$ patients had dribbling of urine and $6 \%$ patients had vomiting / nausea.

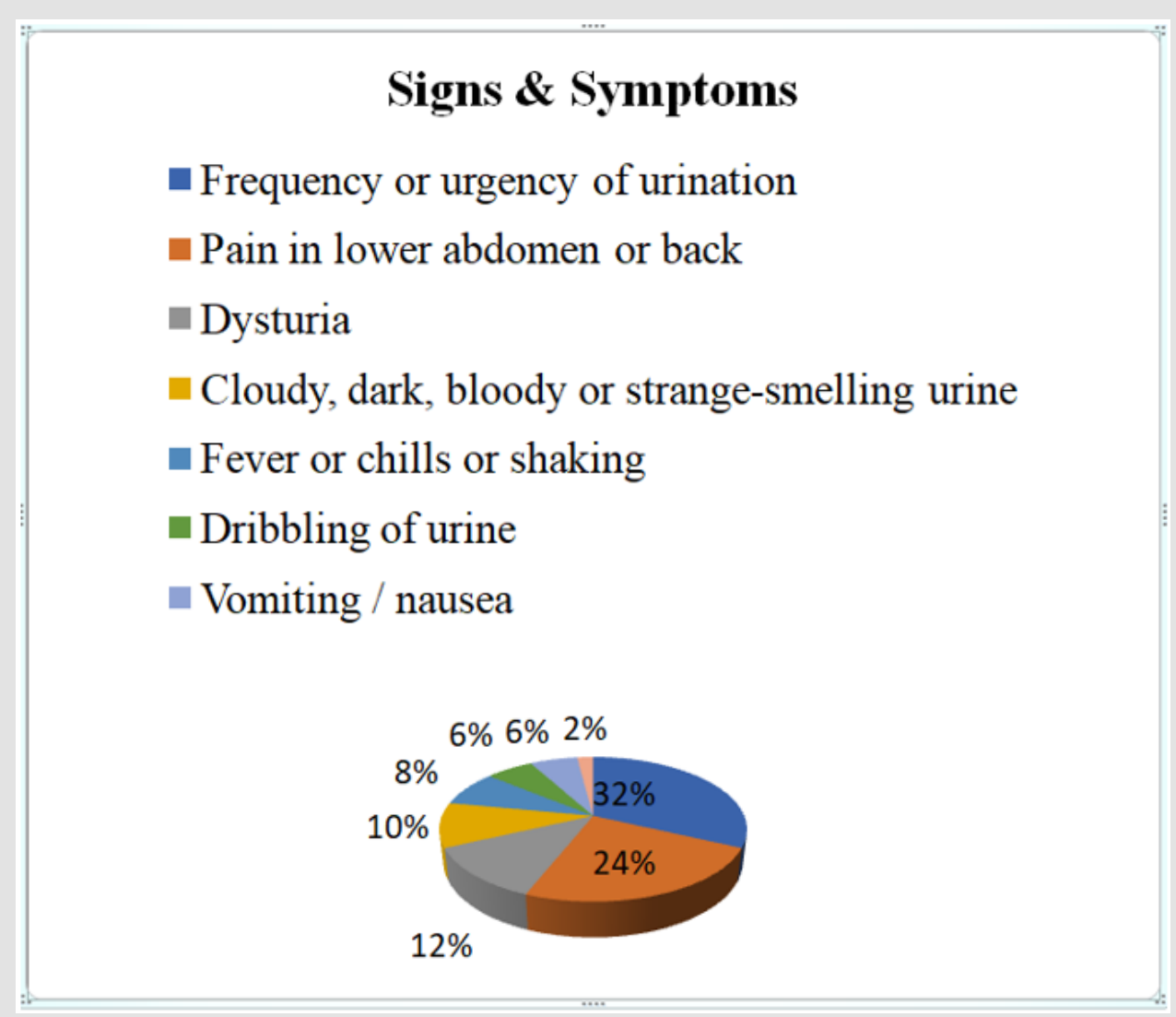

Figure 6: Percentages of Signs and Symptoms of UTI Patients.

Table 6: Signs and Symptoms of UTI Patients.

\begin{tabular}{|c|c|c|}
\hline Signs and Symptoms & Number of Patients & Percentages \\
\hline $\begin{array}{c}\text { Frequency or urgency of urination (with less } \\
\text { urine output) }\end{array}$ & $32 \%$ \\
\hline Pain in lower abdomen or back & $24 \%$ \\
\hline Dysturia (burning pain on urination) & 6 & $12 \%$ \\
\hline Cloudy, dark, bloody or strange-smelling urine & 5 & $8 \%$ \\
\hline Fever (high grade) or chills or shaking & 4 & 3 \\
\hline Dribbling of urine & $3 \%$ & $6 \%$ \\
\hline Vomiting / nausea & $2 \%$ & \\
\hline
\end{tabular}

\section{Diagnostic Test}

\section{a. Comment (Table 7) (Figure 7)}

From the above figure it was seen that the highest proportion of patients had done USG of KUB diagnosis for UTI which was $20 \%$ and the least proportion had done urine culture test in which the growth of Enterococcus faecalis bacteria was found which was only $2 \%$. Among the remaining $18 \%$ patients had done routine microscopic examination, $12 \%$ patients had done urine culture test in which the growth of Escherichia coli (E.coli) bacteria was found, $6 \%$ patients had done urine culture test in which the growth of Klebsiella spp bacteria was found, $8 \%$ patients had done urine culture test in which no growth of bacteria was found , $4 \%$ patients had done IVU test,12\% patients had done USG of whole abdomen and $18 \%$ patients had not done any diagnostic test for UTI. 


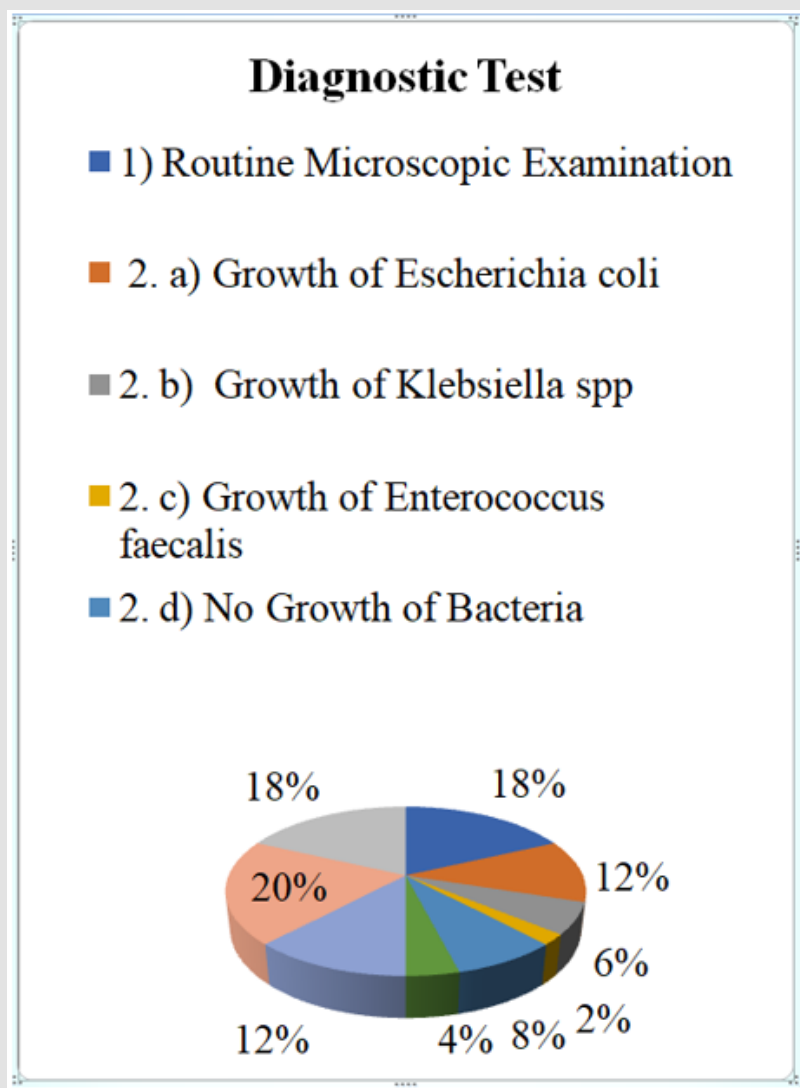

Figure 7: Percentages of Diagnostic Test of UTI Patients.

Table 7: Diagnostic Test of UTI Patients.

\begin{tabular}{|c|c|c|}
\hline Diagnostic Test & Number of Patients & Percentages \\
\hline \multicolumn{3}{|c|}{ 1) Urinalysis: } \\
\hline Routine Microscopic Examination & 9 & $18 \%$ \\
\hline \multicolumn{3}{|c|}{ 2) Urine Culture: } \\
\hline a) Growth of Escherichia coli (E.coli) Bacteria & 6 & $12 \%$ \\
\hline b) Growth of Klebsiella spp Bacteria & 3 & $6 \%$ \\
\hline c) Growth of Enterococcus faecalis Bacteria & 1 & $2 \%$ \\
\hline d) No Growth of Bacteria & 4 & $8 \%$ \\
\hline \multicolumn{3}{|c|}{ 3) Urinary Tract Imaging Techniques: } \\
\hline a)IVU & 2 & $4 \%$ \\
\hline \multicolumn{3}{|l|}{ b) USG } \\
\hline i) USG of Whole Abdomen & 6 & $12 \%$ \\
\hline ii) USG of KUB & 10 & $20 \%$ \\
\hline 4) Not Done Any Diagnostic Test & 9 & $18 \%$ \\
\hline
\end{tabular}

\section{Antibiotic Therapy}

\section{a. Comment (Table 8) (Figure 8)}

From the above figure it was seen that the highest proportion of patients had taken antibiotic therapy only during hospitalization which was $48 \%$ and the least proportion had taken antibiotic therapy before hospitalization \& during hospitalization which was only $4 \%$. Between the remaining $18 \%$ patients had taken antibiotic therapy before hospitalization and $30 \%$ patients had not taken any antibiotic therapy. 


\section{Antibiotic Therapy}

- Before Hospitalization

- During Hospitalization

- Both (Before Hospitalization \& During Hospitalization)

Not Found Any Antibiotic Therapy

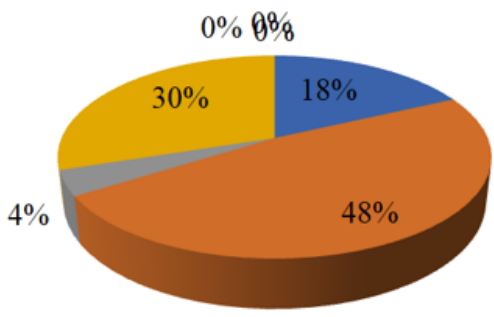

Figure 8: Percentages of Antibiotic Therapy of UTI Patients.

Table 8: Antibiotic Therapy of UTI Patient.

\begin{tabular}{|c|c|c|}
\hline Antibiotic Therapy & Number of Patients & Percentages \\
\hline Before Hospitalization & 9 & $18 \%$ \\
\hline During Hospitalization & 24 & $48 \%$ \\
\hline Before Hospitalization \& During Hospitalization & 2 & $4 \%$ \\
\hline Not Found Any Antibiotic Therapy & 15 & $30 \%$ \\
\hline
\end{tabular}

\section{Used Antibiotic}

\section{a. Comment (Table 9) (Figure 9)}

From the above figure it was seen that the highest proportion of patients had not taken any antibiotic which was $30 \%$ and the least proportion had taken antibiotic related to tetracycline drug class which was only $2 \%$. Among the remaining $28 \%$ patients had taken antibiotic related to cephalosporin drug class, $22 \%$ patients had taken antibiotic related to quinolone or fluoroquinolone drug class, $10 \%$ patients had taken antibiotic related to penicillin drug class, $4 \%$ patients had taken antibiotic related to aminoglycoside drug class, and $4 \%$ patients had taken antibiotic related to nitrofurantoin drug class.

\section{Used Antibiotic}

- Cephalosporin

- Penicillin

- Nitrofurantoin

- Not Used Any Antibiotic
- Quinolone / Fluoroquinolone

\section{- Aminoglycoside}

- Tetracycline

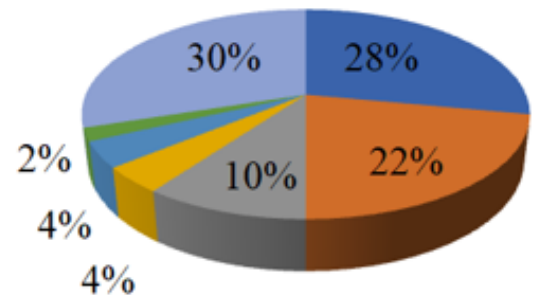

Figure 9: Percentages of Used Antibiotic of UTI Patients. 
Table 9: Used Antibiotic of UTI Patients.

\begin{tabular}{|c|c|c|}
\hline Used Antibiotic & Number of Patients & 14 \\
\hline Cephalosporin & 11 & $28 \%$ \\
\hline Quinolone / Fluoroquinolone & 5 & $22 \%$ \\
\hline Penicillin & 2 & $4 \%$ \\
\hline Aminoglycoside & 2 & $2 \%$ \\
\hline Nitrofurantoin & 1 & $30 \%$ \\
\hline Tetracycline & 15 & \\
\hline
\end{tabular}

\section{Duration of Treatment}

\section{a. Comment (Table 10) (Figure 10)}

From the above figure it was seen that the highest proportion of patients had completed $50 \%$ course of treatment which was $52 \%$ and the least proportion had completed full course of treatment which was only $6 \%$. Between the remaining $24 \%$ patients had completed $25 \%$ course of treatment and $18 \%$ patients had taken only a single dose.

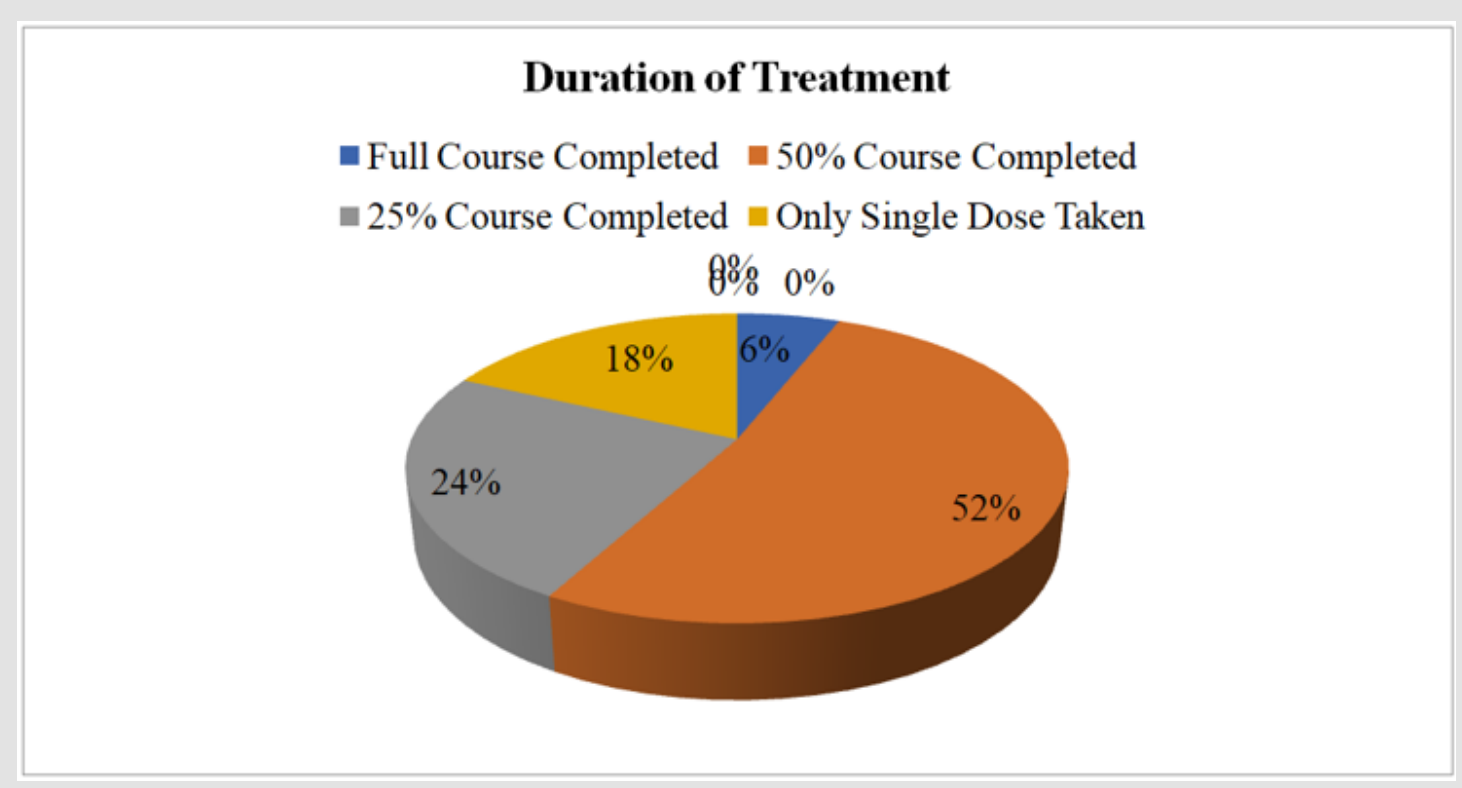

Figure 10: Percentages of Duration of Treatment of UTI Patients.

Table 10: Duration of Treatment of UTI Patients.

\begin{tabular}{|c|c|c|}
\hline Duration of Treatment & Number of Patients & \multicolumn{2}{|c|}{ Percentages } \\
\hline Full Course Completed & 3 & $52 \%$ \\
\hline $50 \%$ Course Completed & 26 & $24 \%$ \\
\hline $25 \%$ Course Completed & 12 & $18 \%$ \\
\hline Only Single Dose Taken & 9 & \\
\hline
\end{tabular}

\section{Associated Disease}

\section{a. Comment (Table 11) (Figure 11)}

abnormalities as associated disease with UTI which was $34 \%$ and the least proportion had cardiovascular disease (CVD), asthma, chronic obstructive pulmonary disease (COPD) and cancerwhich was only $2 \%$ each. Among the remaining $8 \%$ patients had hypertension (HTN), 10\% patients had diabetes mellitus (DM), $4 \%$ patients had chronic kidney disease (CKD), 6\% patients had anemia, 4\% patients had neurological disorders, $8 \%$ patients had multi-diseases and 18\% patients had not found any associated disease with UTI. 


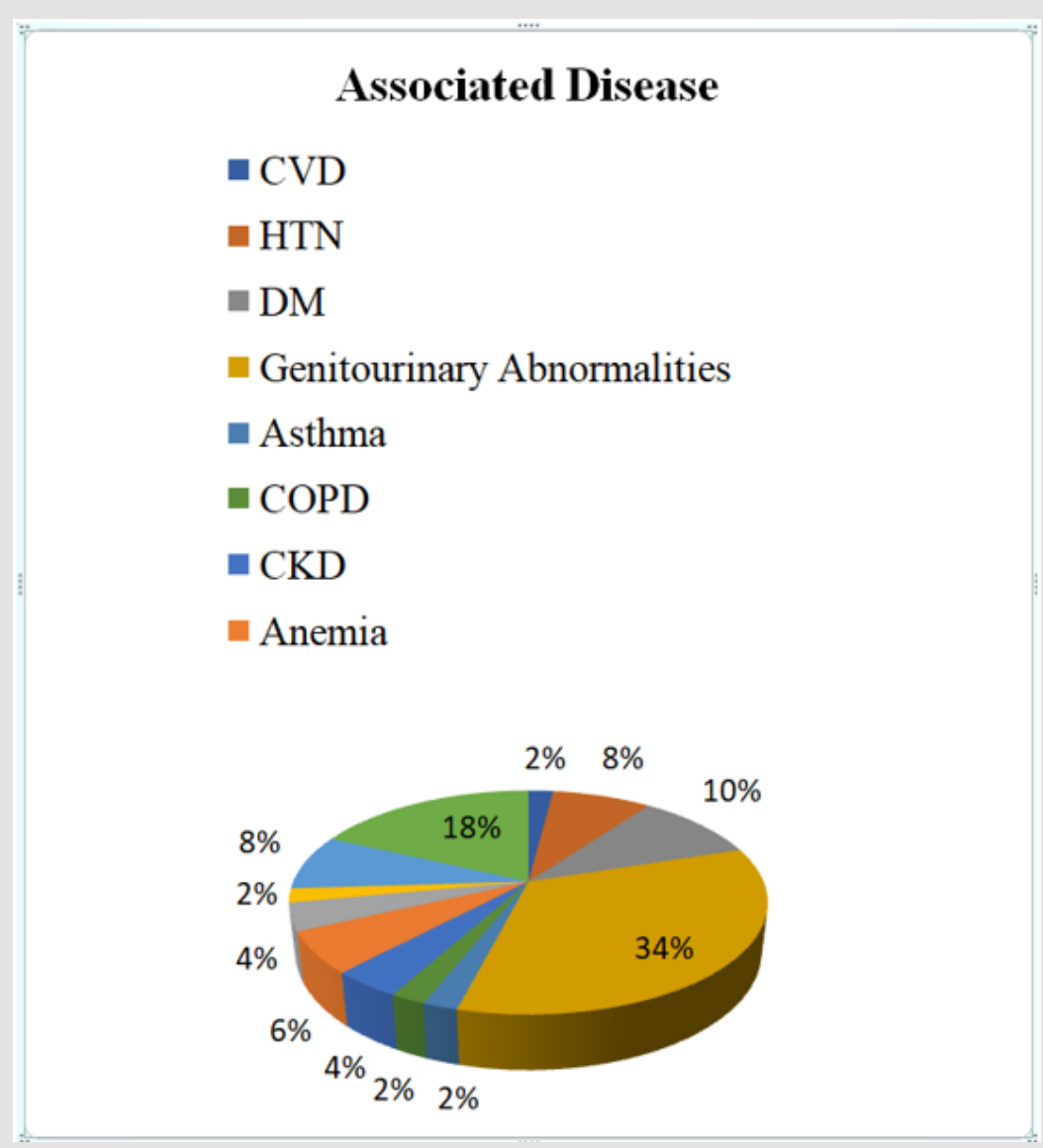

Figure 11: Percentages of Associated Disease of UTI Patients.

Table 11: Associated Disease of UTI Patients

\begin{tabular}{|c|c|c|}
\hline Associated Disease & Number of Patients & Percentages \\
\hline Cardiovascular Disease (CVD) & 1 & $2 \%$ \\
\hline Hypertension (HTN) & 4 & $10 \%$ \\
\hline Diabetes Mellitus (DM) & 5 & $34 \%$ \\
\hline Genitourinary Abnormalities & 17 & $2 \%$ \\
\hline Asthma & 1 & $2 \%$ \\
\hline Chronic Obstructive Pulmonary Disease (COPD) & 1 & $4 \%$ \\
\hline Chronic Kidney Disease (CKD) & 2 & $6 \%$ \\
\hline Anemia & 3 & $4 \%$ \\
\hline Neurological Disorders & 2 & $2 \%$ \\
\hline Cancer & 1 & $8 \%$ \\
\hline Multi-Diseases & 4 & $18 \%$ \\
\hline
\end{tabular}

\section{Awareness Program}

a. Place: The awareness program was carried out around 500 students of different teaching institutes like Buetech academics, Probaha coaching center, Retina coaching center and Udvash coaching center.

\section{b. Provided information:}

I. Briefing to the students about the definition of UTI.
II. Asking to the students if they have any knowledge about the signs and symptoms of UTI.

III. Explaining them how to prevent UTI.

IV. Specifying that the Urologists are the specialists for UTI treatment.

\section{Conclusion}

There has been a lot of concern about increasing the rate of UTI patients in last few years. According to this survey the highest 
proportion of patient's age range was from 21-30 years which was $28 \%$ and the least proportion of patient's age range was from $71-80$ years which was only $2 \% .68 \%$ of patients were male and the remaining $32 \%$ were female patients. $64 \%$ of patients were married and the remaining $36 \%$ were unmarried. The highest proportion of patients was illiterate regarding $46 \%$ and the least proportion had secondary education which was $6 \%$. The highest proportion of patients was from rural area which was $60 \%$ and the least proportion was from slum area which was $14 \%$. The highest proportion of patients had frequency or urgency of urination with less urine output which was $32 \%$ and the least proportion had sense of incomplete emptying of bladder which was only $2 \%$. The highest proportion of patients had done USG of KUB diagnosis for UTI which was $20 \%$ and the least proportion had done urine culture test in which the growth of Enterococcus faecalis bacteria was found which was only $2 \%$. The highest proportion of patients had taken antibiotic therapy only during hospitalization which was $48 \%$ and the least proportion had taken antibiotic therapy before hospitalization \& during hospitalization which was only $4 \%$. The highest proportion of patients had not taken any antibiotic which was $30 \%$ and the least proportion had taken antibiotic related to tetracycline drug class which was only $2 \%$. The highest proportion of patients had completed $50 \%$ course of treatment which was $52 \%$ and the least proportion had completed full course of treatment which was only $6 \%$. The highest proportion of patients had genitourinary abnormalities as associated disease with UTI which was $34 \%$ and the least proportion had cardiovascular disease (CVD), asthma, chronic obstructive pulmonary disease (COPD) and cancer which was only $2 \%$ each. In this research work, awareness program was carried out among the students of different teaching institutes, where the information about prevention and treatment of UTI had provided.

\section{References}

1. Lichtenberger P, Hooton TM (2008) Complicated urinary tract infections. Curr Infect Dis Rep10: 499-504.

ISSN: 2574-1241

DOI: 10.26717/BJSTR.2020.27.004552

MdShahidul Islam. Biomed J Sci \& Tech Res

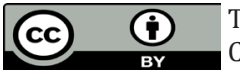

This work is licensed under Creative Commons Attribution 4.0 License

Submission Link: https://biomedres.us/submit-manuscript.php
2. D Prakash, RSSaxena (2013) Distribution and antimicrobial susceptibility pattern of bacterial pathogens causing urinary tract infection in Urban Community of Meerut City, India. ISRN Microbiologyvol 2013: 749629.

3. O Amali, MD Indinyero, EU Umeh, NO Awodi (2009) Urinary tract infections among female students of the university of agriculture, Makurdi, Benue State, Nigeria. Internet Journal of Microbiology 7(2): $1-5$.

4. A Hoberman, M Charron, RW Hickey, M Baskin, DH Kearney, et al. (2003) Imaging studies after a first febrile urinary tract infection in young children. New England Journal of Medicine 348(3): 195-202.

5. V Camacho, M Estorch, G Fraga, Mena E, Fuertes J, et al. (2004) DMSA study performed during febrile urinary tract infection: A predictor of patient outcome. European Journal of Nuclear Medicine and Molecular Imaging 31(6): 862-866.

6. O Olowe, B OjoJohnson, O Makanjuola, R Olowe, V Mabayoje (2015) Detection of bacteriuria among human immuno deficiency virus seropositive individuals in Osogbo, south-western Nigeria," European Journal of Microbiology and Immunology 5(1): 126-130.

7. Cattell WR (1996) Infections of the Kidney and Urinary Tract. Oxford University Press p. 1-26.

8. Obiogbolu CH, Okonko IO, Anyamere CO, AO Adedeji, A Ogun, et al. (2009) Incidence of Urinary Tract Infections (UTIs) among pregnant women in Akwa metropolis, Southeastern Nigeria. Sci Res Essays 4: 820-824.

9. Behzadi P, Behzadi E (2008) The Microbial Agents of Urinary Tract Infections at Central Laboratory of DrShariati Hospital, Tehran, IRAN. Turk Klin Tip Bilim28:445-449.

10. Ayhan N, Basbug N, Ozturk S (1998) Causative agents of urinary tract infections and sensitivity to antibiotics. Microbiol Bull 22: 215-221.

11. Ebie MY, Kandakai Olukemi YT, Ayanbadejo J (2001) Urinary tract infections in a Nigerian Military Hospital. Nig J Microbiol 15: 31-37.

12. Garofalo CK, Hooton TM, Martin SM, Stam WE, Palermo JJ, et al. (2007) Escerichia coli from Urine of Female Pateints with Urinary Tract Infections is Competent for Intracellular Bacterial Community Formation. Infect Immun 75: 52-60.

13. Stamm WE (2001) An Epidemic of Urinary Tract Infections? N Engl J Med 345:1055-1057.

14. WE Stamm, SR Norrby (2001) Urinary tract infections: disease panorama and challenges. Journal of Infectious Diseases 183(s1): S1-S4.

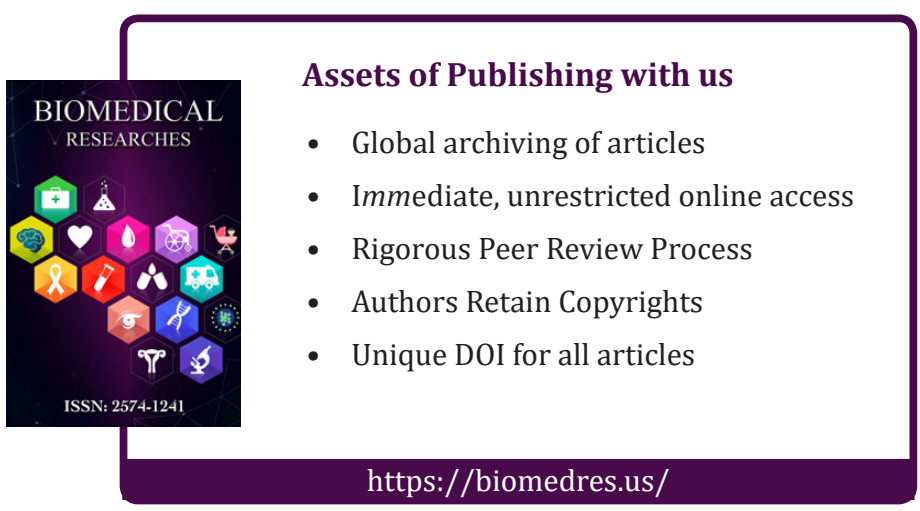

Copyright@ MdShahidul Islam | Biomed J Sci \& Tech Res | BJSTR. MS.ID.004552. 